\title{
Adubação nitrogenada em cobertura em dois cultivares de milho no Cariri-CE
}

\author{
Paulo José de Morais Máximo ${ }^{1}$, Antônio Alves Pinto ${ }^{1}$, Felipe Thomaz da Camara ${ }^{1}$, Antônio \\ Marcos Duarte Mota ${ }^{1}$, Francisca Edcarla de Araújo Nicolau ${ }^{1}$
}

${ }^{1}$ Universidade Federal do Cariri, Centro de Ciências Agrárias e da Biodiversidade, Crato, Ceará, Brasil. E-mail:
moraesmaximojdn@ @otmail.com, antonioalvesaap01@gmail.com, felipe.camara@ ufca.edu.br,
marquinhosagroproduzir@gmail.com, carla_nicolau18@yahoo.com.br

Recebido: 27/03/2018; Aceito: 14/11/2018.

\begin{abstract}
RESUMO
O milho tem importante destaque para a produção de forragem na alimentação animal, com a adubação nitrogenada sendo fundamental para garantir elevados níveis de produtividade. Portanto, o presente trabalho teve por objetivo avaliar a produtividade de massa verde de dois cultivares de milho em função da adubação nitrogenada em cobertura na região do Cariri-CE. O experimento foi conduzido no assentamento Malhada, no distrito de Ponta da Serra, distante $19 \mathrm{~km}$ da sede do município de Crato - CE. Foi utilizado o delineamento em blocos casualizados em esquema fatorial $2 \times 4$, com três repetições, totalizando 24 observações. $\mathrm{O}$ primeiro fator foi dois cultivares de milho híbrido (AG 1051 e FTH 960), e, o segundo, as doses de adubo nitrogenado em cobertura $(0 \%, 50 \%, 100 \%$ e 150\%, referente à dose recomendada). O milho FTH 960 apresentou a maior produtividade de massa verde total, com acréscimo de 19,1\% em relação ao AG 1051. A adubação nitrogenada em cobertura não teve influência sobre a altura da espiga e da planta, a população final, o comprimento e o diâmetro da espiga com palha, mas elevou a produtividade de massa verde para os dois cultivares. Conclui-se que o milho FTH960, com uso de 53,12 $\mathrm{kg} \mathrm{ha}^{-1}$ de nitrogênio em cobertura é o mais indicado para a região do CaririCE.
\end{abstract}

Palavras-chave: Massa verde, componentes do rendimento, Zea mays, ureia.

\section{Nitrogen side dressing fertilization in two maize cultivars in Cariri-CE}

\begin{abstract}
Maize has an important emphasis on forage production in animal feed, with nitrogen fertilization being fundamental to guarantee high levels of productivity. Therefore, the objective this work was evaluating the green mass yield of two maize cultivars as a function of the nitrogen side dressing fertilization in the Cariri-CE region. The experiment was conducted in the Malhada settlement in the district of Ponta da Serra, $19 \mathrm{~km}$ away from the headquarters of the municipality of Crato - CE. A randomized complete block design was used in a $2 \times 4$ factorial scheme, with three repetitions, totaling 24 observations. The first factor was two cultivars of hybrid maize (AG 1051 and FTH 960), and the second were nitrogenous side dressing fertilizer doses $(0 \%, 50 \%, 100 \%$ and $150 \%$, referring to the recommended dose). The FTH 960 maize presented the best results, with higher total green mass yield, with an increase of $19,1 \%$ in relation to AG 1051. The nitrogen fertilization in the cover had no influence on the height of the cobs and plant, the final population, length and diameter of the cob with straw, but increased the yield of green mass, with the total green mass having linear response, for both cultivars. It is concluded that the corn FTH960, with $53.12 \mathrm{~kg} \mathrm{ha}^{-1}$ of nitrogen under cover is the most suitable for the region of Cariri-CE.
\end{abstract}

Keywords: Green mass, corn cobs, Zea mays, doses, urea. 


\section{Introdução}

O milho situa-se entre os cereais mais comercializados no Brasil, em função de ser considerado um alimento com grande poder energético, contendo na sua composição química aproximadamente $60 \%$ de carboidratos, $10 \%$ de proteínas, $4 \%$ de lipídeos, vitaminas e minerais (Fornasieri Filho, 2007). Dessa forma, é utilizado desde a alimentação animal, da qual é o principal insumo, até as indústrias de alto nível tecnológico.

No ano agrícola de 2016/17, a região nordeste teve a terceira maior área cultivada com milho, chegando a aproximadamente 2.425 milhões de hectares, com produtividade média de $2.527 \mathrm{~kg} \mathrm{ha}^{-1}$, porém, ficando atrás das demais regiões do país na produtividade por área (CONAB, 2017). Tais resultados são em função dos vários fatores que contribuem com o insucesso agrícola na região, dentre os quais se destacam a irregularidade pluviométrica, os sistemas tradicionais de cultivo e o manejo cultural associado à ausência de adubação balanceada, principalmente a nitrogenada.

Resultados de experimentos conduzidos sob diversas condições de solo, clima e sistemas de cultivo mostraram que, em geral, os ensaios com a cultura do milho responderam bem à aplicação de nitrogênio (Cruz et al., 2008; Farinelli e Lemos, 2010), fatos também constatados por Goes et al. (2012) ao verificarem que o rendimento de grãos de milho aumentou consideravelmente em função das dosagens de N (20,40 e $80 \mathrm{~kg} \mathrm{ha}^{-1}$ ) aplicadas ao solo.

Conforme Bastos et al. (2008), o nitrogênio é essencial no cultivo de milho, por estar relacionado com o aumento na produtividade. Além disso, está entre os nutrientes requeridos em maiores quantidades pela cultura, fato que contribui para que parte dos produtores apliquem dosagens excessivas, aumentando assim os custos de produção, sem retorno em produtividade.

Segundo Santos et al. (2010), além da escolha adequada da quantidade de adubação nitrogenada em cobertura, é preciso a utilização de cultivares adaptados às condições de cultivo, contribuindo assim para maiores produtividades da cultura do milho.

Desta forma, vários estudos têm sido desenvolvidos por pesquisadores buscando determinar o cultivar mais adaptado aos diferentes ambientes, bem como a dose certa de nitrogênio a ser aplicada na cultura do milho, visando alcançar a máxima produtividade gastando o mínimo possível com fertilizantes nitrogenados (Santos et al., 2010; Valderrama et al., 2011; Carmo et al., 2012; Santos et al., 2013). Contudo, na região Nordeste, são poucos os estudos que determinam a dosagem ideal a ser aplicada em cobertura, tendo em vista os diversos tipos de solos presentes na região.

Com base no exposto, o presente trabalho objetivou estudar a produção e produtividade de matéria verde de dois híbridos de milho irrigado (AG 1051 e FTH 960), em função das diferentes dosagens de ureia em cobertura, na Região do Cariri Cearense.

\section{Material e Métodos}

O experimento foi conduzido no assentamento Malhada, no distrito de Ponta da Serra, distante $19 \mathrm{~km}$ da sede do município de Crato - CE, localizado nas coordenadas UTM de longitude $456513 \mathrm{~m}$ e latitude $9214076 \mathrm{~m}$, com altitude de $398 \mathrm{~m}$. O clima da região, segundo Köppen (Alvares et al., 2013), é o Aw, caracterizado como clima tropical com estação seca no inverno, apresentando temperatura anual entre 24 e $26^{\circ}$ $\mathrm{C} \mathrm{e}$, nos meses mais quentes, entre 26 e $28^{\circ} \mathrm{C}$.

O solo da área experimental é classificado como VERTISSOLO HÁPLICO Órtico típico, de textura argilosa, contendo, na profundidade de $0-20 \mathrm{~cm}$, teores de 304, 370 e $326 \mathrm{~g} \mathrm{~kg}^{-1}$ de areia, silte e argila, respectivamente. Os resultados obtidos com a análise química do solo de $0-20 \mathrm{~cm}$ de profundidade foram: $\mathrm{pH}$ $\left(1: 2,5 \mathrm{H}_{2} \mathrm{O}\right)=6,5 ; \mathrm{P}\left(\right.$ mehlich $\left.^{-1}\right)=14 \mathrm{mg} \mathrm{dm}^{-3} ; \mathrm{K}=1,90$ mmolc dm ${ }^{-3} ; \mathrm{Ca}=151$ mmolc dm ${ }^{-3} ; \mathrm{Mg}=87,4$ mmolc $\mathrm{dm}^{-3} ; \mathrm{Al}^{3+}=0,0$ mmolc dm ${ }^{-3} ; \mathrm{H}+\mathrm{Al}=8,8 \mathrm{mmolc} \mathrm{dm}^{-3}$; $\mathrm{CTC}=252,0$ mmolc $\mathrm{dm}^{-3}$ e V\% $=98$.

Foi utilizado o delineamento em blocos casualizados em esquema fatorial $2 \times 4$, com três repetições, totalizando 24 observações. O primeiro fator foi dois cultivares de milho híbrido (AG 1051 e FTH 960), e, o segundo, diferentes doses de adubo nitrogenado em cobertura $(0 \%, 50 \%, 100 \%$ e $150 \%$, referente à dose recomendada). Cada parcela experimental continha cinco fileiras de milho espaçadas a $1,0 \mathrm{~m}$, com cinco metros de comprimento, o que corresponde a uma área de $25 \mathrm{~m}^{2}$, totalizando uma área experimental de $600 \mathrm{~m}^{2}$. Os cultivares utilizados foram dois híbridos de milho, o AG 1051, híbrido duplo com alto potencial produtivo, e o FTH 960, um híbrido triplo. Ambos são cultivados na região e apresentam ampla adaptabilidade às condições do semiárido Nordestino.

Não foi realizada adubação de fundação, visando obter respostas apenas para a adubação de cobertura, a qual foi realizada aos trinta dias após a semeadura, quando as plantas se encontravam no estágio V6. Foram testadas quatro doses de ureia $(0 \%, 50 \% 100 \%$ e $150 \%)$, de acordo com o recomendado pela Embrapa para a cultura do milho (Pereira Filho, 2013), onde a dose $100 \%$ foi de $64 \mathrm{~kg} \mathrm{ha}^{-1}$ de $\mathrm{N}$, correspondendo a $143 \mathrm{~kg}$ $\mathrm{ha}^{-1}$ de ureia. As demais doses foram variações proporcionais desta recomendada, conforme cada tratamento. $\mathrm{O}$ experimento foi conduzido em sistema convencional, no período entre julho e outubro de 2013, realizando-se, previamente à implantação do experimento, duas gradagens para incorporar as plantas daninhas e romper supostas camadas compactadas 
provocadas pelo pisoteio animal. O revolvimento foi realizado devido à área ser utilizada para pastejo animal no período de entressafra.

A semeadura foi realizada de forma manual por meio da abertura de sulcos espaçados de $1,0 \mathrm{~m}$, depositando-se duas sementes espaçadas a $20 \mathrm{~cm}$ de distância. Desta forma, obteve-se uma população final de 50.000 plantas por hectare. Aos 20 dias após a semeadura (DAS), foi realizado o desbaste para eliminar as plantas excedentes caso fosse verificada a emergência de mais de uma planta por cova, evitandose, assim, a competição intraespecífica.

Utilizou-se o sistema de irrigação por microaspersão, com vazão média por aspersor de $80 \mathrm{~L}$ $\mathrm{h}^{-1}$. Cada aspersor foi posicionado a 4 metros de distância dentro da linha de irrigação e cada linha foi posicionada a $3 \mathrm{~m}$ de distância, proporcionando uma lâmina de irrigação de aproximadamente $6,66 \mathrm{~mm} \mathrm{~h}^{-1}$, com as regas sendo efetuadas a cada dois dias.

Foram avaliadas as seguintes variáveis na cultura do milho: altura das plantas, número de plantas e de espigas por área, comprimento e diâmetro da espiga inteira e massa das plantas e da espiga. A altura das plantas de milho foi avaliada através da medida entre o nível do solo e a inserção da folha bandeira no colmo das plantas. O número de plantas e de espigas foi contado em duas fileiras centrais de cada parcela, cada uma com um metro de comprimento, o que representa uma área de $2,0 \mathrm{~m}^{2}$. O número de plantas e de espigas por hectare foi obtido pela extrapolação dos resultados para hectare.

Na determinação do comprimento e do diâmetro da espiga inteira (com palha), utilizaram-se dez espigas por parcela, escolhidas ao acaso, nas quais foram feitas medições com o auxílio de uma fita métrica e de um paquímetro, respectivamente, e posteriormente feita uma média dos resultados. Para obtenção da massa verde das plantas e da espiga inteira, foram pesadas dez espigas em uma balança semianalítica, com capacidade máxima de $3 \mathrm{~kg}$, precisão de duas casas decimais para gramas e dados extrapolados para quilos por hectare.

Para comparar e interpretar os resultados, os dados foram submetidos à análise de variância pelo teste $\mathrm{F}$, e as médias do fator cultivar foram comparadas pelo teste de Tukey a 5\% de probabilidade, sendo o fator adubação nitrogenada em cobertura submetido à análise de regressão para seleção do melhor modelo significativo. Foi utilizado o programa estatístico Sisvar 5.6 (Ferreira, 2011).

\section{Resultados e Discussão}

Na Tabela 1, nota-se que o coeficiente de variação, de acordo com Pimentel Gomes (2009), foi médio (10 a $20 \%$ ) para altura de planta, massa verde de espigas por hectare e diâmetro da espiga com palha, e baixo $(<10 \%)$ para espigas por planta, comprimento da espiga com palha, massa verde de plantas por hectare e massa total por hectare. Tais valores são considerados normais em pesquisas de campo que são submetidas a inúmeros fatores não controlados.

Observa-se na Tabela 1 que para o fator cultivar, a altura das plantas e o diâmetro da espiga não obtiveram efeito significativo, com média de $165 \mathrm{~cm}$ de altura e de $4,41 \mathrm{~cm}$ para o diâmetro das espigas. Santos et al. (2010), avaliando a produtividade e características agronômicas de seis variedades de milho, encontraram resultados para a altura das plantas maiores que os encontrados nesse trabalho $(220 \mathrm{~cm})$. Tais resultados podem ter ocorrido devido ao fato de os cultivares serem diferentes dos do presente estudo, além do uso de adubação na semeadura e maior dose de nitrogênio em cobertura, sendo parcelada em duas aplicações, o que pode ter favorecido o melhor aproveitamento do nutriente. Na Tabela 1, verifica-se que espigas por planta, comprimento da espiga com palha, massa verde de espigas por hectare e massa total por hectare obtiveram significância $(\mathrm{P}<0,01)$ no fator cultivar. Já para a variável massa verde de plantas por hectare ocorreu significância $(\mathrm{P}<0,05)$.

$\mathrm{Na}$ Tabela 2, nota-se que o FTH 960 apresentou melhores resultados para comprimento das espigas, massa verde de planta e massa, com produtividade de massa verde total de $35.649 \mathrm{~kg} \mathrm{ha}^{-1}$, resultados próximos aos encontrados por Santos et al. (2010), com média de massa total por hectare de $33.800 \mathrm{~kg} \mathrm{ha}^{-1}$, porém, superados por Paziani et al. (2009), que obtiveram média de $50.470 \mathrm{~kg} \mathrm{ha}^{-1}$ no estado de São Paulo.

Ao analisar a adubação de cobertura (Tabela 1), observa-se que a altura das plantas, o comprimento e o diâmetro das espigas não apresentaram modelos de regressão significativos em função da adubação nitrogenada em cobertura, com o nitrogênio não tendo efeito sobre estas variáveis com valores médios para altura das plantas, comprimento e diâmetro das espigas de $160,28,8$ e 4,4 cm, respectivamente. Souza e Saratto (2006), avaliando o efeito de fontes e doses de adubação nitrogenada em cobertura no milho safrinha, obtiveram alturas de planta e de espigas semelhantes às do presente trabalho, porém, com resposta quadrática, atingindo os maiores valores de altura de planta com aproximadamente $60 \mathrm{~kg} \mathrm{ha}^{-1}$ de nitrogênio em cobertura.

Costa et al. (2012) relataram que o comprimento de espiga não apresentou comportamento significativo em função das doses de nitrogênio em cobertura, semelhante ao observado por Goes et al. (2012) ao estudarem o efeito de fontes e doses de nitrogênio em cobertura no milho safrinha, não verificando também efeito das doses no comprimento e diâmetro da espiga. 
Tabela 1. Síntese da análise de variância e da análise de regressão para altura média das plantas (AP), espigas por planta (E/P), comprimento da espiga com palha (CECP), diâmetro da espiga com palha (DECP), massa verde de espigas por hectare (MVE), massa verde de plantas por hectare (MVP) e massa total por hectare (MVT).

\begin{tabular}{cccccccc}
\hline \multirow{2}{*}{ Fontes de Variação } & \multicolumn{7}{c}{ Valores de F } \\
\cline { 2 - 7 } & AP & E/P & CECP & DECP & MVE & MVP & MVT \\
\hline Cultivar (C) & $0,065^{\mathrm{NS}}$ & $77,29 * *$ & $5,96^{* *}$ & $0,11^{\mathrm{NS}}$ & $37,46^{* *}$ & $3,88^{*}$ & $21,04^{* *}$ \\
Adubação (A) & $0,914^{\mathrm{NS}}$ & $12,26^{* *}$ & $1,01^{\mathrm{NS}}$ & $0,34^{\mathrm{NS}}$ & $12,75^{* *}$ & $3,86^{*}$ & $9,17^{* *}$ \\
C * A & $0,263^{\mathrm{NS}}$ & $8,76^{* *}$ & $1,37^{\mathrm{NS}}$ & $0,62^{\mathrm{NS}}$ & $5,52^{* *}$ & $0,37^{\mathrm{NS}}$ & $1,2^{\mathrm{NS}}$ \\
\hline CV\% & 11,89 & 7,97 & 8,45 & 11,32 & 11,78 & 9,91 & 9,32 \\
\hline Linear & $2,26^{\mathrm{NS}}$ & $27,56^{* *}$ & $1,09^{\mathrm{NS}}$ & $0,28^{\mathrm{NS}}$ & $27,23 * *$ & $10,83^{* *}$ & $23,86^{* *}$ \\
\hline Quadrática & $0,01^{\mathrm{NS}}$ & $9,19^{* *}$ & $1,70^{\mathrm{NS}}$ & $0,20^{\mathrm{NS}}$ & $10,84^{* *}$ & $0,01^{\mathrm{NS}}$ & $3,28^{\mathrm{NS}}$ \\
\hline
\end{tabular}

**: significativo $(\mathrm{P}<0,01)$; *: significativo $(\mathrm{P}<0,05)$; NS: não significativo $(\mathrm{P}>0,05)$; $\mathrm{CV} \%$ : coeficiente de variação.

Tabela 2. Síntese do teste de médias para espigas por planta (E/P), comprimento da espiga com palha (CECP), massa verde de espigas por hectare (MVE), massa verde de plantas por hectare (MVP) e massa total por hectare (MVT).

\begin{tabular}{|c|c|c|c|c|c|}
\hline \multirow{3}{*}{ Fator } & \multicolumn{5}{|c|}{ Teste de Médias de Tukey $(\mathrm{p}<0,05)$} \\
\hline & $\mathrm{E} / \mathrm{P}$ & CECP & MVE & MVP & MVT \\
\hline & -unid.-- & ------cm------ & ---- & $--\mathrm{kg} \mathrm{ha}^{-1}$ & ------ \\
\hline \multicolumn{6}{|l|}{ Cultivar (C) } \\
\hline AG 1051 & - & $27,7 \mathrm{~b}$ & - & $17564 \mathrm{~b}$ & $29925 \mathrm{~b}$ \\
\hline FTH 960 & - & $30,1 \mathrm{a}$ & - & $19022 \mathrm{a}$ & $35649 \mathrm{a}$ \\
\hline
\end{tabular}

Médias seguidas pela mesma letra minúscula na coluna não diferem entre si pelo teste de Tukey a 5\% de probabilidade.

Verifica-se, na Tabela 1, que para as variáveis número de espigas por planta e massa verde de plantas por hectare ocorreu interação significativa entre o cultivar e a adubação de cobertura, com estas interações sendo desdobradas nas Figuras 1 e 2.

Para as espigas por planta em função da adubação em cobertura (Figura 1), verifica-se que o melhor modelo de regressão para o AG1051 foi o linear, e para o FTH 960 foi o polinomial de segunda ordem, ambos com diferença significativa $(\mathrm{p}<0,01)$. Ressalta-se que a quantidade de espigas por planta no AG1051 aumentou com o acréscimo de adubação nitrogenada em cobertura, enquanto que o FTH 960 atingiu a produção máxima com aproximadamente $83,33 \%$ da dose recomendada, que corresponde a $56,32 \mathrm{~kg} \mathrm{ha}^{-1}$ de nitrogênio, produzindo 1,93 espigas por planta. Esses resultados são contrários aos obtidos por outros autores (Freire et al., 2010; Santos et al., 2013) ao verificaram que o número de espigas por planta não variou com a aplicação de até $60 \mathrm{~kg} \mathrm{ha}^{-1}$ de nitrogênio.

Verifica-se, ainda, que o milho FTH 960 (Figura 1) obteve maior produção de espigas por planta quando comparado ao AG 1051 até $100 \%$ da dose recomendada, porém, com $150 \%$ do recomendado, ambos os cultivares não diferiram estatisticamente. No entanto, Farinelli e Lemos (2010), estudando a eficiência agronômica do milho em função de doses de $\mathrm{N}$ em cobertura, não verificaram, quando da utilização do cultivar DKB 466, aumento de espigas por planta com a elevação de até $60 \mathrm{~kg} \mathrm{ha}^{-1}$ de nitrogênio em cobertura, porém, obtiveram média de espigas por planta de aproximadamente 2,01, valores superiores aos do presente estudo para ambos os cultivares, com o FTH 960 aproximando-se deste valor para a dose de $50 \%$ da recomendada, com 1,93 espigas por planta.

$\mathrm{Na}$ massa verde de espigas por hectare em função da adubação (Figura 2), observa-se que o modelo de regressão mais representativo foi o linear para o AG1051, e, para o FTH 960, o polinomial de segunda ordem, ambos significativos $(\mathrm{p}<0,01)$. Nota-se, ainda, que ocorreu aumento da MVE no AG1051 com a elevação da dose de nitrogênio, enquanto que o FTH 960 obteve máxima produtividade de MVE $(19074 \mathrm{~kg}$ $\left.\mathrm{ha}^{-1}\right)$, com aproximadamente $83 \%$ da dose recomendada. Carmo et al. (2012), em trabalho para avaliar os efeitos de fontes e doses de nitrogênio em cobertura no desenvolvimento e produtividade do milho, obtiveram aumento linear na massa das espigas em função do aumento da dose de nitrogênio.

Verifica-se, ainda na Figura 2, que o milho FTH 960 obteve melhores resultados que o AG 1051, obtendo maiores produtividades de espigas com a utilização de até $100 \%$ da dose recomendada; porém, com $150 \%$ do recomendado, ambos os cultivares apresentaram valores similares.

Observa-se que o AG 1051 é mais exigente em adubação nitrogenada em cobertura, e, possivelmente, com doses superiores às avaliadas neste estudo, poderia ter resultados superiores ao FTH 960 quanto à massa verde das espigas, porém com o uso de doses muito altas de nitrogênio, o que tornaria o custo de produção elevado. 
Na Tabela 1, observa-se que para o fator adubação as variáveis massa verde de plantas por hectare e massa total por hectare obtiveram significância a 5 e $1 \%$ de probabilidade, respectivamente, sendo que para ambas as variáveis o melhor modelo de regressão foi o linear com significância $(p<0,01)$, com os acréscimos nas doses de nitrogênio proporcionando aumento das massas (Figura 3).

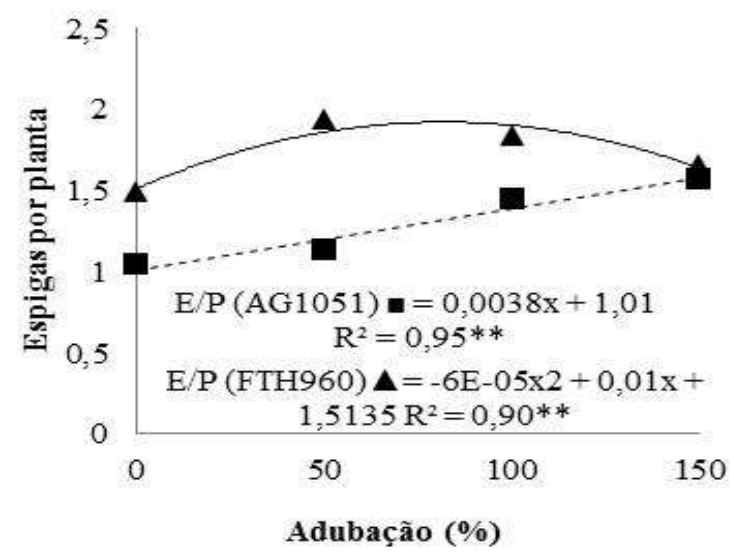

Figura 1. Número de espigas por planta para o FTH 960 (E/P(FTH960)) e para o AG 1051 (E/P (AG 1051)) em função da adubação nitrogenada em cobertura.

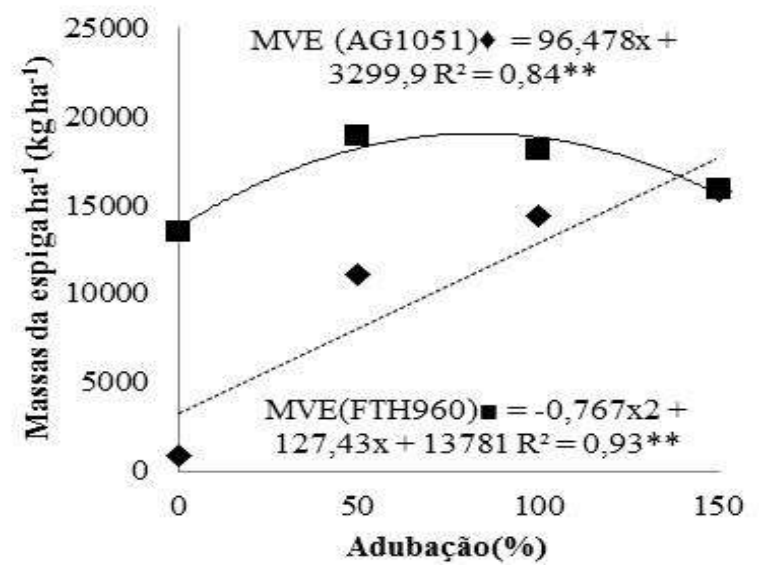

Figura 2. Massa verde de espigas do AG1051 (MVE (AG1051)) e do FTH 960 (MVE (FTH960)) em função da adubação nitrogenada em cobertura.

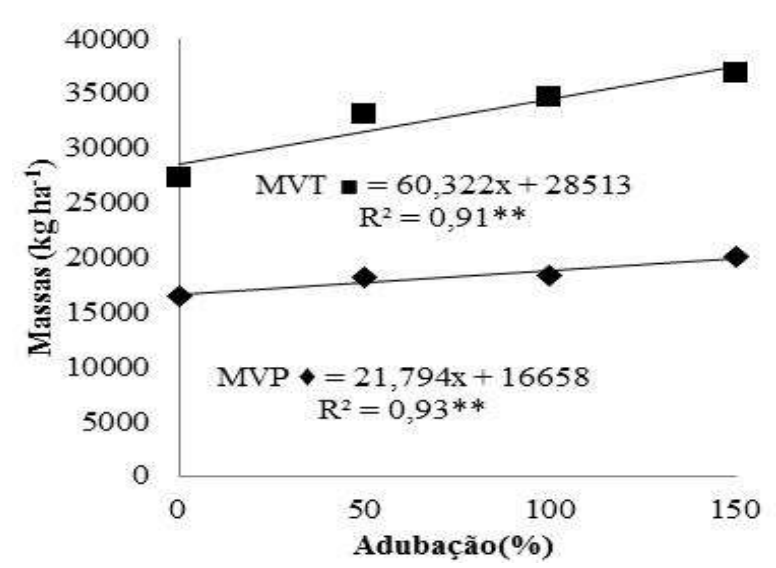

Figura 3. Massa verde de plantas (MVP) e massa verde total (MVT) em função da adubação nitrogenada em cobertura.
Após a análise de todas variáveis, percebe-se que o milho FTH 960 apresentou os melhores resultados, com maior produtividade de massa verde de espigas, de plantas e total, sendo o mais indicado para a região nas condições em que foi realizada a pesquisa. A adubação nitrogenada em cobertura não teve efeito sobre a altura, o comprimento e o diâmetro da espiga com palha, porém, elevou a produtividade de massa verde de plantas, de espigas e total, com a massa verde total tendo resposta linear para os dois cultivares com a dose de até $150 \%$ da recomendada, que no presente estudo corresponde a $96 \mathrm{~kg} \mathrm{ha}{ }^{-1}$ de Nitrogênio, sendo necessários novos estudos para verificar a máxima dose significativa, avaliando-se doses superiores a esta.

\section{Conclusões}

O cultivar FTH960 foi superior ao AG1051 quanto à produtividade de massa verde;

Os dois cultivares responderam bem à adubação nitrogenada em cobertura, sendo recomendado o uso da dose máxima estudada para o cultivar AG1051 (96 kg $\mathrm{ha}^{-1}$ de Nitrogênio) e de $53,12 \mathrm{~kg} \mathrm{ha}^{-1}$ para o FTH960.

\section{Referências Bibliográficas}

Alvares, C. A.; Stape, J. L.; Sentelhas, P. C.; Gonçalves, J. L. M.; Sparovek, G., 2013. Koöppen's climate classification map for Brazil. Meteorologische Zeitschrift, 22, 711-728.

Bastos, E.A.; Cardoso, M.J.; Melo, F. B.; Ribeiro, V.Q.; Andrade Junior, A. S., 2008. Dose e formas de parcelamento de nitrogênio para a produção de milho sob plantio direto. Revista Ciência Agronômica, 39, 275-280.

Carmo, M. S.; Cruz, S. C. S.; Souza, E. J.; Campos, L. F. C.; Machado, C. G., 2012. Doses e fontes de nitrogênio no desenvolvimento e produtividade da cultura de milho doce (Zea mays convar. saccharata var. rugosa). Biosciencie Journal, 28, 223-231.

Costa, N. R.; Andreotti, M.; Gameiro, R. A.; Pariz, C. M.; Buzetti, S.; Lopes, K. S. M., 2012. Adubação nitrogenada no consórcio de milho com duas espécies de Braquiária em sistema plantio direto. Pesquisa Agropecuária Brasileira, 47, 1038-1047.

Companhia Nacional de Abastecimento (CONAB), 2018. Acompanhamento da safra brasileira de grãos. 2017, Brasília Disponível em: http://www.conab.gov.br/OlalaCMS/uploads/arquivos/16_10_ 21_15_32_09_safra_outubro.pdf. (Acesso em: 09 de abril de 2018).

Cruz, S.C.; Pereira, F.R.S.; Santos, J.R.; Albuquerque, A.W.; Pereira, R.G., 2008. Adubação nitrogenada para o milho cultivado em sistema plantio direto, no Estado de Alagoas. Revista Brasileira de Engenharia Agrícola e Ambiental, 12, $62-68$. 
Farinelli. R.; Lemos. L. B., 2010. Produtividade e eficiência agronômica do milho em função da adubação nitrogenada e manejos do solo. Revista Brasileira de Milho e Sorgo, 09, 135146.

Ferreira, D. F., 2011. SISVAR: um computador sistema de análise estatística. Ciência e Agrotecnologia, 35, 1039-1042.

Freire, F. M.; Viana, M. C. M.; Mascarenhas, M. H.T.; Pedrosa, M. W.; Coelho, A. M.; Andrade, C. L. T., 2010. Produtividade econômica e componentes da produção de espigas verdes de milho em função da adubação nitrogenada. Revista Brasileira de Milho e Sorgo, 09, 213-222.

Fornasieri Filho, D., 2007. Manual da cultura do milho. Primeira ed. Funep, Jaboticabal.

Goes, R. J.; Rodrigues, R. A. F.; Arf, O.; Vilela, R. G., 2012. Nitrogênio em cobertura para o milho (Zea mays L.) em sistema plantio direto na safrinha. Revista Brasileira de Milho e Sorgo, 11, 169-177.

Pimentel Gomes, F., 2009. Curso de estatística experimental. Décima quinta ed. FEALQ, Piracicaba.

Santos, R. D.; Pereira, L. G. R.; Neves, A. L. A. Azevêdo, J. A. G.; Moraes, S. A.; Costa, C. T. F., 2010. Características agronômicas de variedades de milho para produção de silagem. Acta Scientiarum, 32, 367-373.

Santos, L. P. D.; Aquino, L. A.; Nunes. P. H. M. P.; Xavier. F. O., 2013. Doses de nitrogênio na cultura do milho para altas produtividades de grãos. Revista Brasileira de Milho e Sorgo, $12,270-279$

Souza, E. F., Soratto, R. P., 2006. Efeito de fontes e doses de nitrogênio em cobertura, no milho safrinha, em plantio direto. Revista Brasileira de Milho e Sorgo, 05, 395-405.

Paziani, S. D. F.; Duarte, A. P.; Nussio, L. G.; Gallo, P. B.; Bittar, C. M. M.; Zopollatto, M.; RECO, P. C., 2009. Características agronômicas e bromatológicas de híbridos de milho para produção de silagem. Revista Brasileira de Zootecnia, 38, 411-417.

Pereira Filho, I. A. 2013 Embrapa Milho e Sorgo. Cultivo do Milho: nutrição e adubação do milho. 2013, p. 25 Brasília Disponível em: http://www.cnpms.embrapa.br/publicacoes/milho_8_ed/feradu ba.htm ( Acesso em: 15 junho de 2013).

Valderrama, M.; Buzetti, S.; Benett, C.G.S.; Andreott, M.; Teixeira Filho, M.C.M., 2011. Fontes e doses de NPK em milho irrigado sob plantio direto. Pesquisa Agropecuária Tropical, 41, 254-263. 